\title{
Proposiciones para la Nueva Ley de Universidades*
}

\section{Fuenmayor Toro, Luis**}

Este año se discute en la Asamblea Nacional la Ley Orgánica de Educación, en la cual es necesario incluir la parte correspondiente a la educación superior, para que ese instrumento legal sea realmente una Ley Orgánica de toda la educación venezolana y no sólo de un segmento de ella, como había sido hasta ahora. Sigo creyendo, a pesar de que algunos compañeros que me acompañaban en el pasado en esta idea hoy no la comparten, que debemos, después de promulgar la Ley Orgánica de Educación, elaborar una Ley de Universidades donde además de estas instituciones se incorporen los politécnicos, los pedagógicos y los institutos de altos estudios, militares y civiles. La producción del conocimiento sería la actividad o función fundamental de esta parte del sistema de educación superior, que además formaría investigadores y profesionales del más alto nivel, todo lo cual estaría a cargo de las instituciones que lo integran y, tendría como objetivos fundamentales, garantizar un mejoramiento continuo de las condiciones de vida y bienestar de nuestros compatriotas, el despegue definitivo del país del subdesarrollo, la adopción de un nuevo modelo de explotación del petróleo, que ponga su acento en la producción de productos petroquímicos y químicos orgánicos, la autarquía alimentaria, el desarrollo científico y tecnológico y el ejercicio pleno de nuestra soberanía.

En la Ley Orgánica creariamos el sistema de educación superior y definiríamos sus instituciones integrantes, su importancia, sus funciones, sus características y sus comunidades académicas. Se reafirmaría el carácter autónomo de las universidades, politécnicos y pedagógicos, pero se deberia hacer énfasis en la responsabilidad que este privilegio conlleva, en lo inaceptable de su perversión y en que el mismo debe entender en función de las actividades académicas institucionales, principalmente las derivadas de la creación intelectual en todas sus formas, las cuales no pueden tener otro límite que las fronteras de la inteligencia humana y los linderos del conocimiento y de la imaginación (Fuenmayor Toro, 1993: 43-49).

Creado el sistema de educación superior, se pasaría a elaborar y promulgar las leyes especiales: Ley de Universidades, Ley de Institutos y Colegios Universitarios, Ley del Financiamiento de la Educación Superior y una (Ley de Financiamiento Especial por diez años para culminar y completar la Planta Física Pendiente de todas las Universidades Públicas Venezolanas), entre las principales. Para estas leyes se debería de dar un plazo de un año. Una Ley de Educación Superior, que

\footnotetext{
* Ponencia dictada en el auditorio de la Facultad de Ciencias Económicas y Sociales. 24/05/2001. En el I Simposio Reforma Universitaria para la equidad y calidad, organizado por el Centro de Estudios de la Empresa. Ensayo publicado en la Revista Debate Abierto \# 16. Mayo 2001. Caracas.
}

* ExRector de la Universidad Central de Venezuela (UCV). Director de la Oficina de Planificación del Sector Universitario (OPSU) del Consejo Nacional de Universidades (CNU). 
abarque todo el sistema, parece una tarea dificil de instrumentar por lo heterogéneo de las instituciones que lo componen, lo que la haria muy extensa e impráctica. Si de algo le sinen at hombre sus vivencias y experiencias, deberiamos recordar que desde 1979 se ha estado tratando de elaborar una Ley de Educación Superior y todos los intentos efectuados han resultado fallidos, pues es muy difícil conjugar en un solo instrumento legal la rica diversidad universitaria con la también extensa heterogeneidad del resto de las instituciones.

Para ayudar y facilitar la discusión que se debe dar en tomo a la nueva ley que regule a las universidades, presentamos un grupo de 8 grandes temas con sus respectivas proposiciones, algunas más afinadas que otras, para el debate abierto de todas ellas, pues han surgido del análisis del funcionamiento de las universidades en el periodo que va desde 1958 a nuestros días y todas de gran impacto para la construcción de la universidad del siglo $X X I$. Helas aquí:

\section{Separación de poderes}

Uno de los mayores problemas con que ha tropezado el funcionamiento de la universidad venezolana y, me atrevería a decir de toda la educación superior del país, ha sido la concentración de poderes que se da en el seno de su máximo organismo directivo: el Consejo Universitario o su equivalente en las universidades experimentales. Estos cuerpos de dirección tienen por ley atribuciones reglamentarias y normativas, a la vez que funciones de ejecución, disciplinarias, electorales y contraloras, sobre las instituciones y sus comunida. des académicas y sobre el personal de apoyo.

Esta concentración de poderes en un único organismo nos lleva a la contraproducente situación de que continuamente sus integrantes son jueces y, a la vez, parte interesada en las situaciones analizadas y en las cuales se debe producir una toma de decisiones, las que en consecuencia no necesariamente obedecen al interés de la institución como un todo $y$, en muchas ocasiones, son incluso contrarias al interés institucional. Se debe prevenir que los consejos directivos o universitarios se corporativicen, práctica común impulsada por los partidos políticos del pasado y que sigue estando vigente a través de sus despojos sucesorales, para que las decisiones producidas no respondan a los intereses de las instituciones, sino beneficien intereses bastardos de individualidades o grupos intra o extra-institucionales. Enfrentar esta situación desde su raíz significa desconcentrar los poderes de manera de distribuirlos entre distintos organismos, todos en principio de una misma jerarquía, integrados por representantes de la comunidad y por autoridades de los distintos programas a ser ejecutados o por profesores, a quienes se exigirá determinadas condiciones de escalafón y tiempo de trabajo en la institución, elegidos por la comunidad académica, constituidos de manera diferente de acuerdo a sus atribuciones, con competencias para la aprobación de pasos diferentes de procesos similares, con funciones complementarias que en forma automática permiten el control de unos organismos sobre los otros (Fuenmayor Toro, 2001: 8) de manera de desarrollar un necesario y eficaz autocontrol institucional con la menor injerencia externa posible o necesaria.

\section{Consejo Universitario o Directivo}

En principio propondriamos la existencia de un Consejo Universitario o Directivo, presidido por el Rector, donde no estaria ninguna otra autoridad ejecutiva de la institución. Sería el máximo organismo de dirección y decisión académica de la universidad, con funciones normativas y reglamentarias, de elaboración de las políticas, de aprobación de los planes de estudios y diseños curriculares, de establecimiento de aranceles y subvenciones, de evaluación de las funciones esenciales universitarias, de autorización para la suscripción de contratos y convenios, la aceptación de herencias y donaciones, la adquisición y enajenación de bienes, la determinación de los pro- 
gramas de concursos y ascensos, la designación de jurados, la aprobación presupuestaria y la creación de carreras, programas, facultades, centros, institutos y demás dependencias, estas dos últimas atribuciones a solicitud del Consejo Ejecutivo a través del Rector.

En este organismo estarian representados los distintos tipos de miembros de la comunidad universitaria en número de acuerdo a su jerarquía y nombrados, con excepción del representante del Ministro de Educación, Cultura y Deportes, por elección directa de los integrantes de cada uno de los grupos del claustro universitario: personal académico, docentes-investigadores-extensionistas a dedicación exclusiva a la universidad, profesionales docentes, personal protesional con funciones docentes que se desempeña a tiempo convencional; Instructores por concurso, docentes a dedicación exclusiva ubicados en el primer nivel de la carrera académica, en etapa de formación como investigadores, como paso previo para ascender al personal académico; estudiantes de pregrado, estudiantes de los postgrados académicos a dedicación exclusiva y el personal académico jubilado. Los representantes de los instructores y de los estudiantes durarán un máximo de dos años en sus funciones y perderán su condición al ascender o graduarse, respectivamente. Los integrantes del Consejo Universitario o Directivo, que representan a los distintos sectores de la comunidad universitaria, mantendrán sus actividades académicas y sólo tendrán dispensa de las mismas en los dias de sesiones del cuerpo. No podrán tener cargo directivo o de coordinación de ninguno de los niveles de la administración académica y el desempeño de sus representaciones no podrá ser remunerado en ninguna forma.

\section{Consejo Ejecutivo}

También seria presidido por el Rector, quien estaria acompañado de los decanos o autoridades equivalentes de núcleos y programas y del resto de las autoridades ejecutivas centrales: las universitarias, directores de investigación, postgrado y extensión y, eventualmente, según el tamaño y las complejidades institucionales, algunos otros funcionarios ejecutivos, cuyo ámbito de acción sea para toda la institución como el Director General de Administración. La mayoría de sus miembros serían electos en el caso de las instituciones autónomas o de universidades experimentales a las que se les haya concedido esta potestad. Sus integrantes estarian dispensados de la realización de las actividades académicas ordinarias, a menos que obtuvieran licencia para mantener un máximo de dos horas diarlas dedicados a la docencia, investigación o extensión, por parte del Consejo Universitario o Directivo.

El Consejo Ejecutivo sería el encargado de la marcha adecuada de las actividades universitarias, del cumplimiento de las leyes y reglamentos por toda la comunidad y por el personal de apoyo y sería el órgano máximo de dirección ejecutiva de las instituciones. Entre sus atribuciones estaría la elaboración del presupuesto anual de ingresos y gastos, las proposiciones de creación de programas, carreras, sedes, núcleos, centros, institutos u otras dependencias; la elaboración de los planes de estudios, la realización de los movimientos del personal administrativo y obrero, el establecimiento de los cupos por carreras y programas, la apertura de los concursos de oposición para el ingreso del personal docente y de investigación, la aprobación del calendario oficial de actividades anuales y la tramitación de los veredictos de concursos y ascensos.

\section{Consejo Disciplinario}

De las violaciones a las normas y reglamentos universitarios por parte de los miembros de la comunidad universitaria, así como de cualquier otra falta cometida por los mismos, que por su índole o extensión tenga implicaciones académicas o institucionales, se ocupará el Consejo Disciplinario. El mismo actuará a iniciativa propia o a solicitud de otros organismos de gobierno universitario, de las autori- 
dades ejecutivas de la universidad y de los profesores y, en el caso de denuncias estudiantiles, abrirá una averiguación administrativa previa a la instrucción del expediente. Estará integrado por profesores electos por los distintos sectores de la comunidad académica (personal académico y estudiantes como antes se definió) y designará de fuera de su seno un abogado con muy buenas credenciales, quien además de ser el Secretario del Consejo dispondrá de una oficina de asuntos disciplinarios y velará por el cumplimiento del debido procesoen la instrucción de los expedientes disciplinarios. Sus integrantes deberán ser miembros del personal académico y estar entre los docentes de los dos más elevados niveles del escalafón universitario (carrera académica). Los miembros del Consejo Disciplinario mantendrán todas sus actividades académicas, con excepción de las que se realicen los días de reunión, pero no podrán tener otra actividad directiva o de coordinación de ningún nivel de la administración académica, ni remuneración ninguna por su desempeño en el organismo.

\section{Consejo Contralor}

Se trataría de un organismo que supliría con creces y con mucho mayor legitimidad las insuficiencias detectadas en las contralorias internas de las universidades en las últimas cuatro décadas. El organismo contralor de la universidad no puede depender del Rector o del Consejo Universitario, como ha ocurrido con las contralorías señaladas sobretodo en los últimos años, pues ambas son instancias que deben ser controladas por esas dependencias con relación a sus ejecutorias administrativas, financieras y académicas. Quien controla no puede depender del ente a ser controlado, pues esto mediatiza o hace incluso desaparecer la capacidad fiscalizadora real del ente contralor.

El Consejo Contralor tendría como brazo ejecutivo a las contralorias internas (Fuenmayor Toro: 2001: 8), las cuales pasarian a depender de él. El Contralor Interno sería el direc- tor de la Oficina de Contraloría y a la vez el Secretario Ejecutivo del Consejo Contralor, quien lo escogeria a través de un proceso de concurso público de credenciales por un período de tres años. El Consejo estaría constituido por representantes electos de los sectores integrantes del claustro universitario, a quines se añadiría la representación del Misterio de Educación, Cultura y Deportes, de la Contraloría General de la Nación, de la Fiscalia General de la República y del Ministerio de Ciencia y Tecnologia.

El ámbito de la acción controlora abarcará todas las dependencias universitarias y todas aquellas entidades donde la universidad tenga participación en su constitución, funcionamiento o financiamiento. Los integrantes del Consejo Contralor miembros del Claustro Universitario no tienen dispensa para la realización de sus actividades académicas normales con excepción de los días de sesión del organismo. Tampoco podrán desempeñar cargos de dirección o coordinación académico-administrativa en ningún nivel de la institución, ni tener remuneración por su labor consejera.

\section{Consejo de Apelaciones}

Seria el organismo superior de las universidades en materia disciplinaria, electoral y de impugnación a las decisiones de los consejos directivo y ejecutivo. Decidiría también en única instancia interna sobre los desacuerdos entre los dos máximos órganos de gobierno universitario: los consejos Directivo o Universitario y Ejecutivo. Serviria también de tribunal de honor en los asuntos que se le sometan a su consideración por vía de arbitraje. La constitución de este cuerpo tiene que prestar especial atención a sus elevadas y fundamentales funciones. Sus integrantes deberian estar "más allá del bien y del mal", para utilizar una expre. sión común muy descriptiva de lo que se quiere. Significa esto que deben ser académicos completamente realizados, con pocos intereses individuales o personales en la institución, pues ya han cumplido con creces con todos los 
dades ejecutivas de la universidad y de los profesores $y$, en el caso de denunclas estudiantiles, abrirá una averiguación administrativa previa a la instrucción del expediente. Estará integrado por profesores electos por los distintos sectores de la comunidad académica (personal académico y estudiantes como antes se definió) y designará de fuera de su seno un abogado con muy buenas credenciales, quien además de ser el Secretario del Consejo dispondrá de una oficina de asuntos disciplinarios y velará por el cumplimiento del debido proceso en la instrucción de los expedientes disciplinarios. Sus integrantes deberán ser miembros del personal académico y estar entre los do. centes de los dos más elevados niveles del escalafón universitario (carrera académica). Los miembros del Consejo Disciplinario mantendrán todas sus actividades académicas, con excepción de las que se realicen los dias de reunión, pero no podrán tener otra actividad directiva o de coordinación de ningún nivel de la administración académica, ni remuneración ninguna por su desempeño en el organismo.

\section{Consejo Contralor}

Se trataria de un organismo que supliria con creces y con mucho mayor legitimidad las insuficiencias detectadas en las contralorías intemas de las universidades en las últimas cuatro décadas. El organismo contralor de la universidad no puede depender del Rector o del Consejo Universitario, como ha ocurrido con las contralorias señaladas sobretodo en los úitimos años, pues ambas son instancias que deben ser controladas por esas dependencias con relación a sus ejecutorias administrativas, financieras y académicas. Quien controla no puede depender del ente a ser controlado, pues esto mediatiza o hace incluso desaparecer la capacidad fiscalizadora real del ente contralor.

El Consejo Contralor tendría como brazo ejecutivo a las contralorias internas (Fuenmayor Toro: 2001 : 8), las cuales pasarian a depender de él. El Contralor Interno sería el direc- tor de la Oficina de Contraloria y a la vez el Secretario Ejecutivo del Consejo Contralor, quien lo escogería a través de un proceso de concurso público de credenciales por un periodo de tres años. El Consejo estaría constituido por representantes electos de los sectores integrantes del claustro universitario, a quines se añadiría la representación del Misterio de Educación, Cultura y Deportes, de la Contraloria General de la Nación, de la Fiscalia General de la República y del Ministerio de Ciencia y Tecnologia.

El ámbito de la acción controlora abarcará todas las dependencias universitarias y todas aquellas entidades donde la universidad tenga participación en su constitución, funcionamiento o financiamiento. Los integrantes del Consejo Contralor miembros del Claustro Universitario no tienen dispensa para la realización de sus actividades académicas normales con excepción de los días de sesión del organismo. Tampoco podrán desempeñar cargos de dirección o coordinación académico-administrativa en ningún nivel de la institución, ni tener remuneración por su labor consejera.

\section{Consejo de Apelaciones}

Sería el organismo superior de las universidades en materia disciplinaria, electoral y de impugnación a las decisiones de los consejos directivo y ejecutivo. Decidiria también en única instancia interna sobre los desacuerdos entre los dos máximos órganos de gobierno universitario: los consejos Directivo o Universitario y Ejecutivo. Serviria también de tribunal de honor en los asuntos que se le sometan a su consideración por vía de arbitraje. La constitución de este cuerpo tiene que prestar especial atención a sus elevadas y fundamentales funciones. Sus integrantes deberían estar "más allá del bien y del mal", para utilizar una expre. sión común muy descriptiva de lo que se quiere. Significa esto que deben ser académicos completamente realizados, con pocos intereses individuales o personales en la institución, pues ya han cumplido con creces con todos los 
requisitos que la universidad les exigio a lo largo de toda una fructifera vida académica. Estamos hablando de profesores académicos de gran talla, con el máximo escalatón posible, con título de doctor, con más de 20 años en la universidad y con obra escrita publicada. Deben ser electos por el personal académico de los dos niveles más elevados del escalafón y por los estudiantes regulares del último año de las carreras del nivel de licenciatura y quienes se encuentren en el último año de su maestria o doctorado. Durarian unos cuatro años en sus funciones, continuarian realizando sus actividades académicas normales y sólo dejarían de hacerlo los días de reunión del cuerpo. No podrian desempeñar ningún cargo de dirección o de coordinación académico-administrativa en ningún nivel de la institución, ni tener remuneración como integrantes del Consejo.

Los miembros del Consejo escogerian fuera de su seno al doctor en derecho que asumiria la Secretaria Ejecutiva del Cuerpo, quien tendría bajo su conducción a la Oficina de Apelaciones, la cual dispondria del personal mínimo necesario para el cabal desempeño del Consejo de Apelaciones.

\section{Consejo Nacional de Universidades (CNU)}

Aunque se trata en principio de un organismo extrauniversitario de coordinación de las actividades, de las universidades, algunas de sus atribuciones, entre ellas las disciplinarias, le dan un claro carácter suprauniversitario, por lo que es necesario incorporarlo en el análisis que venimos realizando sobre esta materia. En él también se dan las limitaciones, incongruencias y viclos, que hemos anotado anteriormente para los consejos universitarios. En efecto, la presencia en su seno de los rectores de todas las universidades, en una suerte de cargo representativo, impide no sólo el análisis objetivo de los problemas existentes, sino a veces incluso el reconocimiento mismo de la existencia de problemas. Nos encontramos ante la situación ya descrita de que los actores son jueces y partes al mismo tiempo, lo que impide o por lo menos dificulta en alto grado la visión objetiva de la situación.

De persistir en la próxima legisiación esta estructura, sobre ello no me pronuncio todavía, la misma no debería incorporar en su seno a los rectores, sino se debería buscar otro tipo de representación o mejor de integración del cuerpo, que lo transformara en un foro para la discusión rica y objetiva sobre la educación universitaria: sus aspectos positivos, sus 10gros, sus reservas, sus posibilidades futuras, al mismo tiempo que sus problemas, sus limitaciones, sus distorsiones, vicios y corruptelas. Foro donde se diera una actitud positiva en la dirección de la transformación y el cambio pro. fundos, $\sin$ las mezquindades que muchas veces acompañan estos procesos.

Habría que prestarle atención a las calificaciones de los integrantes del CNU del futuro, pues sólo con personal académico realmente formado, de talla, puede construirse un organismo que se aparte del subdesarrollo mental, académico y político, donde ha estado por espacio de por lo menos tres décadas. Académicos con obra escrita, con escuela formada, con el máximo nivel en el escalatón, con doctorado y con muchos años en el sector universitario, deberian ser los candidatos a constituir el CNU, sin importar la universidad de proveniencia. No serían representantes de ninguna institución; serían miembros integrantes de un organismo político de la academia superior venezolana. De la misma manera deberian ser escogidos los estudiantes: sólo los de mejor rendimiento en toda su carrera y los mejores de los mejores postgrados académicos. Presidiría el Ministro de Educación, Cultura y Deportes, a quien supliría el Viceministro de Educación Superior; tendría su secretario ejecutivo y sus oficinas asesoras, con funcionarios del mismo nivel académico que el resto de los integrantes. Un espacio también para la participación del Ministro de Ciencia y Tecnología, para el de Finanzas, el de Planificación y para la em- 
presa petrolera estatal, la cual se tiene que convertir en la principal financiadora de la ciencia y la tecnologia en el país.

\section{Especializaciones y Postgrados Académicos}

La Ley de Universidades vigente tiene muy poco texto dedicado a los postgrados, a pesar de la importancia de los mismos para el desarrollo del pais y particularmente para la educación universitaria. Esto se debe a que la Ley data de 1958, cuando el desarrollo de los postgrados nacionales era muy reducido. La reforma del año 1970, momento en que ya había un cierto desarrollo de los postgrados nacionales, no tocó este tema pues sus objetivos fueron meramente político-partidistas: asalto a las estructuras de poder universitario, principalmente de la Universidad Central de Venezuela y, someter a ésta a los perversos efectos del clientelismo partidista, que originó un crecimiento burocrático del cual todavía es víctima nuestra UCV.

La futura legislación deberá favorecer la formación de postgrado en el país, para promover el desarrollo de los mismos. Además, crear postgrados latinoamericanos, que permitiria un esfuerzo mancomunado potenciador (Fuenmayor Toro, 1991: 44-48).

La próxima legislación universitaria debería dejar completamente claro la existencia de dos lineas de desarrollo diferentes de los postgrados universitarios: las especializaciones y los postgrados académicos. En los primeros se forma un especialista, es decir un profesional que prestará un mejor y mayor ser. vicio a la sociedad al profundizar su conocimiento de un área cada vez más restringida del conocimiento. Adquiere conocimientos, destrezas manuales e intelectuales, habilldades para el ejercicio profesional de un sector del saber cada vez más reducido y en ello se desempeña y hace carrera. No se trata de un investigador cientifico o humanístico, no se trata de alguien entrenado para realizar tareas de investigación en ciencias sociales, se trata de alguien que profundizó en el conocimiento de un campo menos amplio del saber. Para expresarlo en lenguaje corriente diriamos que se trata de una persona que "sabe cada vez más de menos". Esto no significa que en su formación profesional no se pueda incluir el requisito de la elaboración y presentación de una tesis o trabajo especial de grado, que tendría como finalidad entrenarlo en el manejo de bibliografia y en la comprensión de trabajos de investigación. El especialista aplica conocimientos; el investigador los produce. He all la diferencia.

\section{Formación de Investigadores}

Los postgrados académicos, por su parte, forman investigadores de dos niveles de complejidad: el de maestría y el de doctorado. Es conveniente dar una definición opéracional de lo que consideramos es un doctor y asi también entender lo que significa el nivel de maestría, el cual tiende a desaparecer en las universidades más avanzadas. Un "doctor" es una persona formada y entrenada para realizar investigación científica original y de alta calidad sin supervision". Un "magister" realizar también investigación científica, pero de menor originalidad, de menor calidad y requiere de cierta supervisión. El término "investigación cientifica" es utilizado en su sentido más amplio, por lo que se aplica también a las humanidades y a las ciencias sociales.

La formación de investigadores tiene que ser realizada a dedicación exclusiva y no puede durar menos de dos años de actividades académicas diarias. En relación con la duración de los doctorados y las maestrías es necesario también reglar la duración máxima de los mismos. En un país como el nuestro, donde se requiere la formación de unos 20 mil investigadores en los próximos años, para poder alcanzar la cifra de un investigador por cada un mil habitantes, indicador recomendado para paises con el desarrollo de Venezuela, es totalmente absurdo, contraproducente $e$ incomprensible, la exagerada duración de los postgrados académicos. Mientras en centros de 
excelencia en el exterior un doctorado se puede hacer perfectamente en tres años, en nuestras universidades se tarda más de cinco años. Algo similar ocurre con las maestrías. Debe establecerse legalmente que las maestrías pue. dan finalizarse en dos años y los doctorados en tres, lo cual es perfectamente posible si se entiende que se cursarán a dedicación exclusiva. Las actividades de investigación deben constituir el eje curricular de este tipo de postgrado y deben estar presentes desde el inicio mismo de la actividad académica. La escolaridad formal debe reducirse al minimo indispensable y todo esto debe señalarse en el próximo instrumento legislativo. Los estudiantes de estos postgrados requieren de la asesoría permanente de un tutor o supervisor, quien tiene que ser un investigador en el área de investigación asumida por el estudiante y deben culminar con una tesis de grado y las publicaciones correspondientes en revistas arbitradas y acreditadas. Esto claramente significa que muchas de las maestrías y doctorados existentes, sobretodo en el sector privado, no reúnen los requisitos académicos necesarios para ser consideradas como tales, pues son a tiempo muy parcial y no disponen de tutores de la calidad requerida para estos elevados fines. Muchas maestrias actuales son simples especializaciones con tesis, por lo que no capacitan ni forman realmente para la investigación como se supone deberian hacer. Éstos son elementos a considerar en la próxima legislación universitaria, que debe favorecer a la universidad pública en doctorados y maestrías y limitaros en las instituciones privadas a aquellos cursos que cumplan totalmente con los requisitos exigidos.

\section{Reestructuración del Pregrado}

El desarrollo de los postgrados, por una parte $y$, las necesidades del pals de graduar profesionales en el menor tiempo posible, por la otra, hacen impostergable una revisión de los estudios de pregrado con especial énfasis en la duración de los mismos. Muchos conteni- dos de los programas actuales son repetitivos - innecesarios, mientras que otros pueden perfectamente pasar a niveles educativos superiores, lo que significa que se impone una reducción de la duración de las carreras del nivel de licenciatura a cuatro años, 10 cual debe ser impulsado y ordenado a través de la legisla. ción futura.

Una medida de este carácter favorece los intereses de los estudiantes en general, pero particularmente de aquéllos de bajos recursos, quienes no disponen de financiamiento para mantenerse como estudiantes por periodos prolongados y tendrían mayores posibilidades de culminar exitosamente sus carreras si la duración de las mismas fuera menor. Se favorece también el Estado, pues se reduce el costo de formación de los estudiantes en un 20 por ciento por lo menos, lo que permite la posibllidad de incorporación de un número mayor de estudiantes al sistema educativo universitario. Se favorece también la sociedad en su conjunto, al disponer en menor tiempo de profesionales preparados y adiestrados para servirle.

El acortamiento de las carreras, incluso de las técnicos superiores, que deberian pasar a durar unos dos años, permitiría además una revisión de los programas de estudios de manera de ajustarlos y adaptarlos a los requerimientos reales del pais y al desarrollo del conocimiento y del ejercicio profesional y técnico respectivos. Se harian entonces mucho más pertinentes socialmente los estudios de pregrado.

Dentro de esta revisión estaría la incorporación en el pregado del ejercicio profesional supervisado como para la obtención del grado, tal y como ocurre desde hace bastante tiempo en carreras como la medicina, en la cual los estudiantes ejercen como médicos durante un año en los servicios de salud públicos, tanto hospitalarios como ambulatorios, prestando de esa forma un extraordinario servicio a toda la colectividad, preferentemente a los sectores más pobres de la población, pero por sobretodo formándose y entrenándose en la práctica clínica y de salud pública, luego de haber adquirido e incorporado la formación teóri- 
ca. Se podria, en muchas disciplinas, sustituir la elaboración de la tesis de licenciatura por este ejercicio profesional supervisado. La tesis - trabajo de grado de licenciatura quedaria restringido a aquellos programas en ciencias y humanidades, donde se forman licenciados con el propósito de incorporarlos más adelante a la carrera académica, es decir al campo de la investigación científica y humanistica. Esta reducción del número de potenciales tesistas es, al mismo tiempo, una bendición para estudiantes y profesores de escuelas donde es imposible atender como debe ser al estudiante en busca de tutor para su trabajo de tesis.

\section{Personal docente y de investigación}

La experiencia acumulada durante todos estos años de vigencia de la actual Ley de Universidades nos señala que no todos los do. centes están reaimente interesados en hacer carrera académica en la universidad, razón por la cual muchos incumplen con sus ascensos a pesar de ser profesionales de gran calidad y muy exitosos en su campo en otros sectores de la vida nacional. Esta situación se aprecia con mayor claridad en las escuelas de formación profesional, donde existe el libre ejercicio de la profesión y la posibilidad de contratar con muchos prestadores de servicios. Médicos, abogados, ingenieros, odontólogos, arquitectos, administradores, contadores, periodistas, psicólogos, bioanalistas, son ejemplos de profesiones en las que es posible hacer carrera en empresas estatales y privadas o simplemente en el ejercicio profesional individual.

Otra verdad es que las instituciones universitarias no realizan investigación científica en todas las áreas de su actividad docente, ni todos los profesores se requieren a dedicación exclusiva en todas las carreras y programas que se desarrollan. Esto IImita las posibilidad de realizar investigación de manera consuetudinaria a sollo una parte de los docentes universitarios: aquéllos que están a dedicación exclusiva. Son ellos quienes pueden formarse como investigadores, pues disponen del tiempo institucional para ello a diferencia de los docentes a tiempo parcial, quienes tienen otras obligaciones con otros empleadores o en su trabajo privado. Son ellos también quienes luego pueden disponer de tiempo para la realización de labores de investigación, pues están todo el tiempo en la institución. Es necesario tomar en cuenta estas experiencias en la próxima legislación, a objeto de adaptarla a las necesidades y posibilidades reales de las universidades. Una proposición que surge de la práctica de años es la de dividir a los docentes universitarios y los de los politécnicos y pedagógicos en dos categorias: el personal académico y los profesionales docentes (Fuenmayor Toro, 1996: 14-15).

\section{Personal Académico}

Son los protesores que se desempeñan a dedicación exclusiva, quienes constituyen el personal de planta de las instituciones, responsable de su permanente funcionamiento, que obligatoriamente deben realizar todas las labores académicas y dentro de éstas la de investigación, para lo cual deben formarse. Están también obligados a seguír la carrera académica institucional o carrera del investigador, que establezca la legislación universitaria futura (Fuenmayor Toro, 1996: 14-15).

Su ingreso es por concurso de oposición público ante jurado calificado, cuyos miembros deben estar por lo menos en el tercer nivel del escalatón, si se trata del ingreso como instructor 0 , en el nivel inmediato supe-

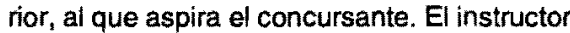
se considerará personal en formación como investigador y aspirante, por lo tanto, llegará a ser personal académico. Este personal tiene la obligación de ascender en el escaláón, por lo menos hasta el penúttimo nivel, tiene el derecho y el deber de integrar mayoritariamente los jurados de los concursos, de los ascensos y de las tesis de maestrías y doctorados. Son también quienes pueden ser electos como autoridades en los distintos organismos de cogobier- 
no universitario y quienes pueden ser designados para el desempeño de cargos académicoadministrativos o como miembros dela Comisión Electoral.

Deben establecerse requisitos mínimos de permanencia en el escalatón y requisitos para el ascenso, de manera de terminar con esa estabilidad absoluta actualmente existente para los profesores, que conspira contra la calidad de los docentes-investigadores, pues en muchas instituciones basta con realizar un mínimo esfuerzo, generalmente sólo en el campo de la docencia de pregrado, para pasarse la vida como "profesor universitario". Este sector docente no deberia ser menor del 60 por ciento del total de docentes de las universidades y debería estar homogéneamente repartido entre todos los programas dictados por la universidad. Podrían establecerse diferencias en esta proporción de acuerdo al tipo de carreras dictadas, con una proporción mayor del personal académico en las facultades de ciencias y humanidades, por lo menos en aquellas carreras y programas no profesionales.

En las instituciones superiores privadas se debería obligar a tener por lo menos un 25 por ciento de su planta docente, no directiva, a dedicación exclusiva y homogéneamente repartida entre todos sus programas. Estos docentes-investigadores estarian adscritos, según su especialidad, a grupos o unidades de investigación de instituciones públicas, donde realizarian obligatoriamente labores de investigación durante un día completo de cada semana, lo que redundaria en beneficio del docente, de la enseñanza que imparta y de su institución de origen. La unidad o grupo receptor se beneficiará al disponer en su trabajo investigativo de un personal con potencialidades para desempeñarse como investigador. Este tiempo les sería contado dentro de su contratación por la institución privada correspondiente.

\section{Profesionales Docentes}

Se trata de profesionales cuya carrera no se realiza en el sector universitario sino fue- ra de éste, en otros sectores públicos o privados, pero que se requieren como docentes para completar la formación protesional de alumnos de pre y postgrado, principalmente en aquellas carreras de ejercicio profesional liberal. Serian contratados a tiempo convencional, por un máximo de 7 u 8 horas, sin obligación de realizar labores de investigación. No participan en la elección de las autoridades ejecutivas de la universidad, aunque pueden tener su representación en algunos de los organismos de cogobierno. Se trataria, en principio, de profesionales muy bien formados, de alta calidad, con suficientes conocimientos y experiencias para ser transmitidos a los estudiantes.

\section{Carrera Académica}

La crisis económica venezolana, que se expresa en todas sus dimensiones a partir del 18 de febrero de 1983, produjo un deterioro acentuado de las remuneraciones de los docentes universitarios y de la educación en general, que llevó a una disminución importante de sus niveles de vida y a la ocurrencia de movilizaciones y luchas por incrementos salariales en la segunda mitad de la década de los ochenta. El instrumento jurídico utilizado para respaldar la legalidad de los planteamientos profesionales fueron las llamadas "Normas de Homologación de Sueldos y Beneficios Adicionales", que inicialmente habian sido cuestionadas por los docentes universitarios ante los tribunales competentes de la República. Perdidos los juicios legales, los profesores asumieron la aplicación de las Normas como una forma de compensar la devaluación del salario, pues las mismas ordenan ajustar los sueldos de los docentes-investigadores universitarios tomando como criterio el incremento del costo de la vida según el Banco Central en los dos años inmediatos anteriores a la producción del incremento. Esto ha permitido compensar parcialmente el deterioro de los sueldos de los profesores universitarios y reducir sus nefastas consecuencias.

La homologación salarial, sin embargo, nofue acompañada de una homologación aca- 
démica, por lo que si bien los sueldos para un mismo nivel y dedicación de un profesor eran similares en las distintas universidades del país, los requisitos de formación, preparación y desempeño académico no eran similares ni para el ingreso ni para el ascenso en el escalafón académico universitario. A pesar de ser éste un hecho claro, ha sido imposible corregirlo pues las universidades gozan de autonomia en la administración académica de su personal, lo que significa que la homologación salarial ha devenido en una injusticia que iguala salarialmente lo que es diferente académicamen. te. Esta sítuación y los bajos salarios han concurrido como elementos importantes en la baja estima que la carrera de los profesores-investigadores tiene dentro de los profesionales. cuestión que compromete seriamente el desarrollo de la academia universitaria. Hace falta por lo tanto, la creación de un sistema nacional de carrera académica, que brinde a los profesores universitarios del sector público remuneraciones e incentivos acordes con su preparación, nivel y desempeño académico. Se trata ahora de homologar académicamente al profesor universitario, para hacer equivalentes los niveles del escalafón dentro de las distintas universidades pública. Se quiere también distinguir a quienes tienen un desempeño particularmente bueno o incluso excepcional, por la via de otorgar remuneraciones diferenciadas que respondan a una mayor productividad e importancia de las contribuciones del personal. Con esto se pretende estimular el desempeño académico del docente, que si lo examinamos a través de las cifras no parece ser muy bueno. Así, en la actualidad solamente el 5,6 por ciento de los profesores activos a dedicación exclusiva y tiempo completo han obtenido el grado de doctor.

Instrumentar la carrera académica nacional constituirá un elemento vital en la tarea de elevar la calidad de nuestra educación universitaria y nos colocará en mucho mejores condiciones para enfrentar el reto de mejorar el nivel educativo de la población venezolana. Sin esta condición es importante pensar en in- dependencia y soberania nacionales; serian palabras sin contenido ninguno, caeríamos en la demagogia más perjudicial si continuáramos utilizando esos ideales sin posibilidades reales de alcanzarlos.

\section{Criterios para su instrumentación}

El programa será nacional y estará fuera del sistema académico-administrativo de las universidades. Estará dirigido solamente al personal académico de las universidades y no a los profesionales docentes y se aplicará inicialmente sólo a los profesores activos. Quienes aspiren a ser acreditados en el programa deberán demostrar la realización de por lo menos dos de las actividades esenciales de las universidades, pero una de éstas deberá ser la actividad creadora de conocimientos $u$ otras formas de creación intelectual.

El nivel que se asigne al docente-investigador en la carrera académica no afectará la posición que tenga en el escalafón en su universidad, pero el profesor podrá recibir la dife. rencia de remuneraciones a su favor si fuera el caso. Esta diferencia de sueldo, producto de que las remuneraciones asignadas a los niveles de la carrera académica nacional estấn por encima de los nivele equivalentes del escalafón universitario, seria considerada como sueldo mientras el profesor la siga percibiendo, por lo que tendría impacto en las prestaciones sociales del académico y en su pensión de jubilación si llegare a ser el caso.

En la carrera académica se ingresa, se permanece, se asciende, se egresa y se reingresa. Esto significa que las posiciones logradas no lo son de por vida, a menos que el esfuerzo académico se siga realizando y el profesor continúe cumpliendo con los requisitos de permanencia en un nivel o de ascenso al nivel inmediatamente superior. Para el ingreso deberia haberse cumplido con el requisito de haber ingresado en el personal académico universitario por concurso de oposición público, realizado ante un jurado calificado. La ubicación deberia responder al tiempo como perso- 
nal académico, a los grados obtenidos en estudios de postgrado y a la productividad demostrada en trabajos de investigación publicados, formación de investigadores, calidad de sus actividades docentes e importancia de sus trabajos extensionistas para la institución, para las comunidades, para sectores económicoso de servicios y para el país.

\section{Evaluación y Acreditación}

La evaluación externa obligatoria, efectuada por los organismos gubernamentales calificados para ello, con el propósito de garantizar la existencia de patrones mínimos de calidad para la creación de programas académicos o para que los mismos continúen funcionando, debe ser incorporada en los textos legales futuros del sector universitario y de la educación superior en general. Esta evaluación tiene por objeto comparar y ajustar el sery el quehacer de las instituciones educativas superiores con su debe ser, de manera de garantizar una educación y funcionamiento de calidad en todos los aspectos del funcionamiento de las instituciones: académicos, organizativos, administrativos y financieros.

Mientras la evaluación institucional tendría un carácter obligatorio, la acreditación tendría carácter voluntario y estaria reservada para todos aquellos programas académicos, cuya calidad estuviera por encima de las condiciones mínimas aceptables determinadas por el proceso de evaluación ya señalado. La acreditación estaria entonces midiendo los esfuerzos institucionales para lograr la excelencia.

Dentro de este proceso se incluye la necesidad de disponer de un sistema de asignación y distribución presupuestaria técnicamente elaborado, que dé respuesta a una exigencia de los universitarios que data desde hace 4 décadas el presupuesto justo (Fuenmayor Toro, 1995: 55-73). Darie contenido a esta exigencia, que significa simplemente la asignación de unos recursos que permitan el cumplimiento de las actividades universitarias en forma cabal, según el tipo de las actividades aca- démicas que realice, con relación al número de estudiantes de pre y postgrado, con el número de profesores estrictamente necesario en función de los requerimientos académicos, sin despilfarro, con una burocracla de apoyo ajustada realmente a las necesidades institucionales, con un manejo austero de los recursos pero sin insuficiencias que comprometan la calidad de las actividades. Se deben incorporar indicadores de gestión que permitan la asignación y distribución objetiva de los recursos y así debe ordenarlo la nueva legislación, con lo cual no sólo se cumple con los postulados anteriores sino se garantiza la equidad en la asignación y distribución entre las distintas universidades. La legislación también debe incorporar la utilización de indicadores de desempeño, como un medio de estimular el mejoramiento continuo de la calidad en función de lograr la excelencia en aquellas institucionales que asi lo decidan y se esfuercen, además en el sentido de utilizar más eficientemente sus recursos financieros y su talento humano.

Si a lo anterior se agrega el otorgamiento y desarrollo de zonas rentales a todas las instituciones, la creación del Fondo de Financiamiento de las mismas y las contrataciones con el Estado para proveerlo de bienes y servicios (Fuenmayor Toro, 1995: 55-73) se habría resuelto el problema del financiamiento de toda la educación superior venezolana. Al tocar el caso de los ingresos propios debe quedar claro que se trata de un derecho de estas instituciones pero no de una obligación, que pudiera interferir perversamente en el óptimo desempeño de las actividades esenciales de las universidades. No se puede presionar indebidamente a los investigadores universitarios para su transtormación en "empresarios".

\section{Aspectos Electorales Novedosos}

Voy a tratar de resumir algunas modificaciones y adiciones con relación a la actual Ley de Universidades, que la práctica de años ha dejado claro que deben ser instrumentadas prontamente. 
Nueva Ley de Universidades en Venezuela

Fuenmayor Toro, Luis

- La figura del Vicerrector Administrativo debe desaparecer y ser sustituida por un Director general de Administración, quien sería designado por el Rector, de quien dependería directamente. Debemos recordar que el cuentadante es el Rector y por lo tanto responsable ante las leyes de la administración de la institución, razón por la cual si el Vicerrector Administrativo no es de su confianza simplemente to aparta y asume el control administrativo de la institución, a través de directores designados directamente por él.

- La elección de las autoridades universitarias, el tren ejecutivo de las instituciones, debe ser por planchas y no nominal, pues se requiere elegir un equipo coherente, unido, sólido, que dirija la institución con el menor número de contradicciones. Otra posibilidad es que se elija únicamente el Rector y éste designe posteriormente su equipo de trabajo, el cual podría ser removido si no llegara a funcionar adecuadamente. Podría extenderse a 5 años el periodo rectoral y a 4 el de los decanos y equivalentes. Los directores, coordinadores y similares durarían tres años en sus funciones y podrían ser extendidos sus periodos hasta por uno 0 dos años más. como máximo, según acompañen a la gestión rectoral o de nivel de decanato, respectivamente.

- El volo de los estudiantes debe ser directo como ya se ha hecho en la mayoría de las instituciones y sólo deben votar los estudiantes regulares. Su peso debe seguir siendo equivalente al 25 por ciento de los votos del personal académico. La participación en los organismos del cogobierno universitario estará restringida a los cursantes del último bienio. No podrán ser representantes estudiantiles quienes sean al mismo tiempo empleados u obreros universitarios, pues dejan de representar a los estudiantes para representar al sector laboral al que pertenezcan, por una parte, y por la otra porque sus posiciones y deci- siones pueden ser perversamente controladas por sus jefes académicos $y$ administrativos en facultades o similares. Participarán en la elección de autoridades universitarias, de decanos o similares, de sus representantes en los consejos Universitarios y Contralor y de los profesores integrantes de los consejos Disciplinario y de Apelaciones, en este último caso sólo vo. tarian los estudiantes del último año de las carreras de nivel de licenciatura.

- Los estudiantes de los postgrados académicos, siempre que estén a dedicación exclusiva en sus estudios, deben tener derecho al voto para elegir sus representantes en los consejos Universitarios y Contralor, para la elección de autoridades académico-administrativas (Universitarias y decanos o equivalentes) y para la elección de los profesores de los concejos Disciplinario y de Apelaciones, en este último caso sólo votarán los estudiantes del último año de maestría y doctorado. Su número se sumará al de los estudiantes de pregrado en la integración de la parte estudiantil del claustro.

- Debe instaurarse, sin excepción ninguna, el requisito de ser doctor y profesor asociado o titular, para poder ser autoridad universitaria y decano de facultad o equivalente. Se debería tener, además, una antigüedad de por lo menos 15 años para ocupar estas posiciones. Para la representación profesoral o integración por profesores de los consejos se debe poseer el escalatón de Profesor Agregado y 10 años de antigüedad, por lo menos, con excepción de los integrantes del Consejo de Apelaciones, quienes deberían ser profesores titulares, doctores y tener más de 20 años de antigũedad en la institución. La representación de los estudiantes de pregrado siempre será de alumnos regulares del ültimo bienio de la carrera del nivel de licenciatura; en programas que se cursen por unidades crédito, los representantes deberán haber aprobado todos los crédi- 
tos obligatorios de los primeros seis semestres, si la licenciatura dura 10 semestres 0 , de 4 semestres, si la licenciatura dura 8 semestres, como se está proponiendo. La de los estudiantes de postgrado siempre será de estudiantes de doctorado. La de los profesionales docentes será la de uno de los miembros de este sector, al igual que los instructores serán representados por un instructor que tenga porto menos seis meses de trabajo universitario.

- Debe reducirse en forma importante el peso del voto de los profesores jubilados (Fuenmayor Toro, 1996: 18) a un valor de no mayor del 15 por clento del número de profesores (personal académico) activos. La práctica de años le ha demostrado a los universitarios que el pasado, representado por los jubilados, no puede determinar el futuro institucional. Los jubilados, que en poco tiempo serán tan o más numerosos que los profesores activos, asisten a votar teniendo en mente la universidad que dejaron años atrás, con su correlación anterior de fuerzas, sus grupos políticos, sus viejas necesidades y los problemas de entonces, todo to cual ha cambiado y puede mcluso haber desaparecido totalmente. En muchas ocasiones acuden al proceso asistidos por alguno de los candidatos, quienes los dirigen y prácticamente deciden por ellos, sin importarles la imagen de irrespeto hacia la dignidad del anciano profesor.

- Lo señalado anteriormente no significa en cambio que un profesor jubilado perteneciente al personal académico no pueda desempeñarse, si es electo, como autoridad universitaria o decano, ya que ésta sería una decisión del claustro universitario y no personal del interesado. Podrian darse las circunstancias de necesitarse al frente de la institución o de uno de sus progra mas a una figura de determinadas caracteristicas que se encuentre en condición de jubilado. La misma tendria derecho a ser elegible, aunque no sea un elector completo pues su voto no es igual al del personal activo.

- Los instructores deben votar para elegir sus representantes en aquellos órganos del cogobiemo integrados con representatividad de los distintos sectores de la comunidad académica. No deben votar para elegir autoridades universitarias ni decanos o equivalentes.

- Los profesores contratados y los auxiliares docentes deben seguir sin derecho a voto, ya que se trata de personal transitorio, de nivel académico menor (auxiliares docentes) y ser una minoría con relación al resto del personal docente: personal académico y profesionales docentes. Otro elemento a ser considerado con relación a su participación electoral es lo presionable de ambos sectores dada su inestabilidad laboral.

- El claustro universitario debe ser redefinido de acuerdo a la nueva composición de la planta docente y debe agregársele atribuciones adicionales a la elección de las autoridades universitarias. En su composición participaría el personal académico, tal y como ya fue caracterizado anteriormente, los estudiantes de pregrado y aquéllos de los postgrados académicos, todos ellos con un peso equivalente al del 25 por ciento del personal académico activo $y$ el 25 por clento del número de votos que alcanzaren, según la equivalencia aprobada, los académicos jubilados. Los jubilados del personal académico seguirán en el claustro pero sus votos equivaldrían a sólo un 15 por ciento del número de votos de los profesores activos (personal académico). Con relación a los egresados, mantener su participación en el claustro no tienen ningún sentido, nada fue notorio o importante de esta participación en los años transcurridos desde 1958. Lo mismo ocurre con la representación de este sector en los organismos de cogobierno, donde se han dedicado más a ob- 
tener prebendas en función personal o de pequeños grupos, que a representar al sector de los egresados e integrarlos y comprometerlos con la institución que los formó al más alto nivel. Con relación a sus atribuciones, el claustro deberia ser el organo de consulta sobre la revocatoria del mandato de las autoridades universitarias, mediante referéndum revocatorio, una vez cumplidos los extremos constitucionales y que imponga la Ley. A este organismo deberian ser sometidos aquellos asuntos que, por su trascendencia, no puedan dejarse en los organismos ordinarios de dirección o aquellas materias que hayan generado contradicciones insuperables entre grupos o sectores importantes de la comunidad, a través de referendos consultivos.

- Alargados los periodos gubemamentales universitarios no se justifica la reelección de ningún nivel de autoridades, ni universitarias ni de otros niveles, en el periodo gubernamental inmediato siguiente. El impedimento de la reelección debe ser también para los cargos de autoridades designadas por el Ejecutivo, pero aplicado después que la institución cumpla sus primeros 6 años. Estos impedimentos debenentenderse para el desempeño del mismo cargo o para otro cargo de mayor o menor jerarquía. Esta norma obligaria a quien es nombrado a cumplir sus obligaciones y funciones, sin mediatizarse ni mediatizar el cargo en función de una reelección.

- Debe reducirse el costo burocrático gubernamental en las universidades y en las otras instifuciones de educación superior. La práctica puntofijista fue la de hacer más costoso el gobierno universitario, tanto incrementando innecesariamente el número de cargos de gobierno como elevando también innecesariamente la jerarquía de los cargos, de manera de disponer de una mayor y mejor oferta de cargos académico-administrativos para ser distribuidos entre la dirigencia partidista siempre dis- puesta "sacrificarse" por el país. En estos momentos se trata de utilizar mucho más eficientemente los recursos, mediante una drástica reducción del número de los cargos de gobierno y de la jerarquía de los mismos. Es inaceptable, por ejemplo, que los núcleos de la Universidad de Oriente sean decanatos mientras que los de la Universidad Ezequiel Zamora sean vicerrectorados, cuando estos últimos son muchísimo más pequeños, con menor número de estudiantes y profesores y menos trabajadores que los primeros. Algo similar ocurrió con los institutos politécnicos que pasaron a constituir la Universidad Experimental Politécnica.

He presentado algunas ideas para una nueva Ley de Universidades, las cuales son producto de años de experiencia, estudio y reflexiốn sobre la situación universitaria venezolana, que he tenido la ocasión de palpar desde muy diversas posiciones: desde la perspectiva del estudlante ucevista, del dirigente estudian. til combativo y revolucionario, del profesor joven a dedicación exclusiva, que se esfuerza por ser un buen docente y formarse como investigador; del estudiante de postgrado en una universidad de primera en el mundo desarro. llado, del profesor investigador ya formado, del Director de Escuela reconocido por la eficiencia de su trabajo, del dirigente gremial exitoso y además gerente de previsión social de los profesores, momento en que comencé una reflexión seria y cientificamente cimentada sobre la universidad venezolana (Fuenmayor Toro, 1986: 1); del representante de los profesores en el Consejo Universitario, del rector de la primera casa de estudios del pais y desde la perspectiva de un gobierno transformador. No se trata entonces de prejuicios, ni recetas de otros lugares, sino del resultado de una intensa práctica social y política y un profundo estudio e investigación. Como investigador científico sé perfectamente que el último paso del proceso de conocer y producir conocimientos es someter nuestras hipótesis a la crítica de nuestros pares. De eso se trata en esta materia tam - 
bién. También opino, desde que me convenció de ello Juan de Jesús Montilla, que un investigador llega a lo más elevado de su carrera cuando está en condiciones de hacerle propuestas a su país en su campo de trabajo. Aquí está más que un resumen de las ideas con sus explicaciones. Hay una blbliografia más extensa aún que puede ser consultada de inmediato. Apreciaria un análisis objetivo, centrado en el contenido de los escrito y no en las supuestas intenciones que pueda haber detrás del mismo. Bienvenidas otras proposiciones, siempre que sean respaldadas y tratadas con la misma seriedad con la que nosotros lo hemos hecho y lo hemos venido haciendo sistemáticamente desde hace poco más de dos décadas.

\section{Bibliografía citada}

Fuenmayor Toro, Luis (1993). "Reflexiones sobre la autonomía y democracia universitarias". Cuadernos Nuevo Sur Sudaca, Nº 5. p.p. 43-49, Abril-Junio. Caracas.

Fuenmayor Toro, Luis (2001). "EI control en las universidades". Panorama. Cuerpo 2. p.p. 8. 06, Marzo. Maracaibo.

Fuenmayor Toro, Luis (1991). "El desarrollo de postgrados nacionales $y$, aún mejor, latinoamericanos nos permitirá enfrentar los retos del futuro en la dificil coyuntura actual". Aula Magna. Año 2. $N^{\circ} 2$ y 3. p.p. 44-48. Mayo. Caracas.
Fuenmayor Toro, Luis (1996). "Propuesta para una nueva Ley Universitaria: ingreso y ascenso en el escalatón del personal académico". Ulitimas Noticias. Suplemento Cultura. p.p. 14-15, 25-02. Caracas.

Fuenmayor Toro, Luis (1995). "El financiamiento universitario: antecedentes y propuestas". En Luis Fuenmayor Toro. "Universidad, Poder y Cambio". Capitulo 3. p.p. 55-73. Fundapriu, Fapuv y Secretaría de la UCV. Eds. Abril. Caracas.

Fuenmayor Toro, Luis (1996). "El voto universitario de los profesores jubilados". El Globo. P.p. 18. 08, Julio. Caracas.

Fuenmayor Toro, Luis (1998). "De nuevo sobre el Proyecto de Ley de Educación Superior". Uitimas Noticias. Suplemento Cultural. p.p. 1-3. 24, Mayo. Caracas.

Fuenmayor Toro, Luis (1986). "Hacia la definición de una política universitaria" Editorial Gaceta apucv/ipp. Año 7. No 47. p.p. 1-2. Junio, Caracas.

Fuenmayor Toro, Luis (1986). "Conocer la Universidad que tenemos. Una tarea de primer orden". Editorial Gaceta apucv/ipp. Año 7. $N^{\circ} 48$. p.p. 1. Julio-Agosto. Caracas. 